\title{
Ambulation from Bedridden - Patient with Double Hemiplegia
}

\author{
Takizawa, $\mathbf{S}^{1}$. Kimura, $\mathbf{T}^{2}$. Kijima, $\mathbf{H}^{3}$. Nagaoka, $K^{4}$. Kanai. $\mathbf{S}^{5}$. \\ Morita, $Y^{6}$. Nagasawa. $H^{7}$. Endo, $S^{8}$. Takizawa. $K^{9}$. \\ ${ }^{1}$ Biophilia Institute of Rehabiliaid company (E-mail: takizawa@ biophilia.biz). ${ }^{2}$ Nippon Medical \\ School, Tokyo. ${ }^{3}$ Kijima Orthopedics Office, ${ }^{4}$ Nagaoka Hospital, Chigasaki-shi. \\ ${ }^{5}$ Shounanikuseien. Kamakura-shi ${ }^{6}$ Kawasaki Medical University. Hospitail, Okayama. \\ ${ }^{7}$ Kitasato university, Sagamihara-shi. ${ }^{8}$ Keio University Hospital, Tokyo. ${ }^{9}$ Geriatric Facility \\ Shonannooka, Chigasaki-shi.
}

\begin{abstract}
Most of all the patients with double-hemiplegia due multiple infarctions who become bedridden cannot reacquire walking. We have rehabilitated a bedridden inpatient with double-hemiplegia, mainly with the motivative exercise according to the instructions of the Takizawa method rehabilitation in a hospital. A woman, 91 years old at the time of hospital admission had improved ADL, reacquired walking after being bedridden, became independent of toilet activities and maintained independence of the activities of daily living (ADL) for 3 years. We report the feasibility of the rehabilitation process of the Takizawa method and the progress of ADL.
\end{abstract}

Keywords: double-hemiplegia, motivative exercise, Takizawa method, reacquired walking,

\section{Background}

Most of all the patients of double-hemiplegia due to multiple infarctions who become bedridden cannot reacquire walking even if there are no abnormal X-ra documented findings that originate from the external injury ${ }^{1)}$. Also, we had reported the fact that 59 people in 193 inpatients in the bedridden hospital had reacquired walking after being bedridden by the motivative exercise according to the Takizawa rehabilitation method. We are studying the effect of Takizawa method since $1987^{2)}{ }^{3)}$. We enforced this case study with the permission of the hospital director and the inpatient.

\section{Purpose}

We propose the rehabilitation method based on the new general idea due to reporting the case and the effectiveness of using a walker in the acquisition of walking. Similar rehabilitation method has been completed in almost 190 inpatients by four aides and one physiotherapist 5 days a week. The woman described in this report is one of those inpatients and this case is a representative example of the result. We adamantly contribute this idea and means to the world by announcing the method that is available for bedridden geriatric patients to reacquire walking.

\section{Methods}

Case: 95 years old woman. Initial K.S. Case history: From January 1995, increased incontinence both urination and feces and progressive walking disturbance due to osteoarthritis of the hip and knee. On April 81995 , the patient was found unable to stand up by the family the next morning. At that time, double hemiparesis (+), anisocoria (+), speech disturbance(-), vomiting(-), and urination incontinence(+). She couldn't walk, had become bedridden and needed to use a diaper. On May 5, she could not eat followed by vomiting(+), so she was treated with a drip infusion (Lact-ringer) and rectal suppository (Nauserin) in the other hospital. On May 11, She was transferred to Nagaoka hospital from the other hospital with using a stretcher. Medical history: multiple cerebral infarctions, arthropathia of both knees and bilateral cataracta postoperative. 53 years old: Hospitalized for two months by hepatitis. 56 years old: osteoporosis. 88 years old: bilateral cataracta were operated, right deficiency hemiparesis. Chief complaint: neck and lower back pain, Apraxia of gait and Remained contractures of bilateral knees.

\subsection{Purpose and evaluation}

The purpose of the rehabilitation, which the doctor directed was an improvement of the joint contractures and to improve muscle strength. The physiotherapist evaluated (fair+) for muscle motor testing on both 
upper and lower extremities on May 15, 1995. The Range of Motion (ROM) tests were shown in table 1. She required aide for all of ADL. (She needed help to roll over and for taking in the sitting position. If she used the backrest, she could maintain the sitting position. She could neither use a wheelchair nor take a standing position.) There was neither a consciousness disorder, difficulty in speech, vision nor hearing disorder. There was neither dementia nor bedsores. The process of rehabilitation of this case was shown in table 2 .

Table 1. Range of Motion (ROM) test for the lower extremities

\begin{tabular}{|c|c|c|c|c|c|c|c|c|c|c|c|}
\hline & & \multicolumn{2}{|c|}{$\begin{array}{l}\text { Flexion(Dorsiflexi } \\
\text { on) }\end{array}$} & \multicolumn{4}{|c|}{$\begin{array}{l}\text { Extension(Plantar Abduction } \\
\text { Flexion) }\end{array}$} & \multicolumn{2}{|c|}{ Internal Rotation } & \multicolumn{2}{|c|}{ External Rotation } \\
\hline & & $1-1$ & $1-2$ & $1-1$ & $1-2$ & $1-1$ & $1-2$ & $1-1$ & $1-2$ & $1-1$ & $1-2$ \\
\hline \multirow[t]{2}{*}{ Hip } & right & $100^{\circ}$ & normal & & & $30^{\circ}$ & normal & $20^{\circ}$ & normal & $20^{\circ}$ & normal \\
\hline & left & $90^{\circ}$ & normal & & & $30^{\circ}$ & normal & $20^{\circ}$ & normal & $40^{\circ}$ & normal \\
\hline \multirow[t]{2}{*}{ Knee } & right & $130^{\circ}$ & $130^{\circ}$ & $-30^{\circ}$ & $-30^{\circ}$ & & & & & & \\
\hline & left & $140^{\circ}$ & $130^{\circ}$ & $-20^{\circ}$ & $-20^{\circ}$ & & & & & & \\
\hline \multirow[t]{2}{*}{ Ankle } & right & $0^{\circ}$ & $0^{\circ}$ & $40^{\circ}$ & $50^{\circ}$ & & & & & & \\
\hline & left & $0^{\circ}$ & $0^{\circ}$ & $40^{\circ}$ & $50^{\circ}$ & & & & & & \\
\hline
\end{tabular}

Range of Motion (ROM) test for the lower extremities (1-1) is evaluated on May 15, 1995, (1-2) is evaluated on October 11, 1995.

The table 2 (The rehabilitation process of Takizawa program and the progress of ADL.)

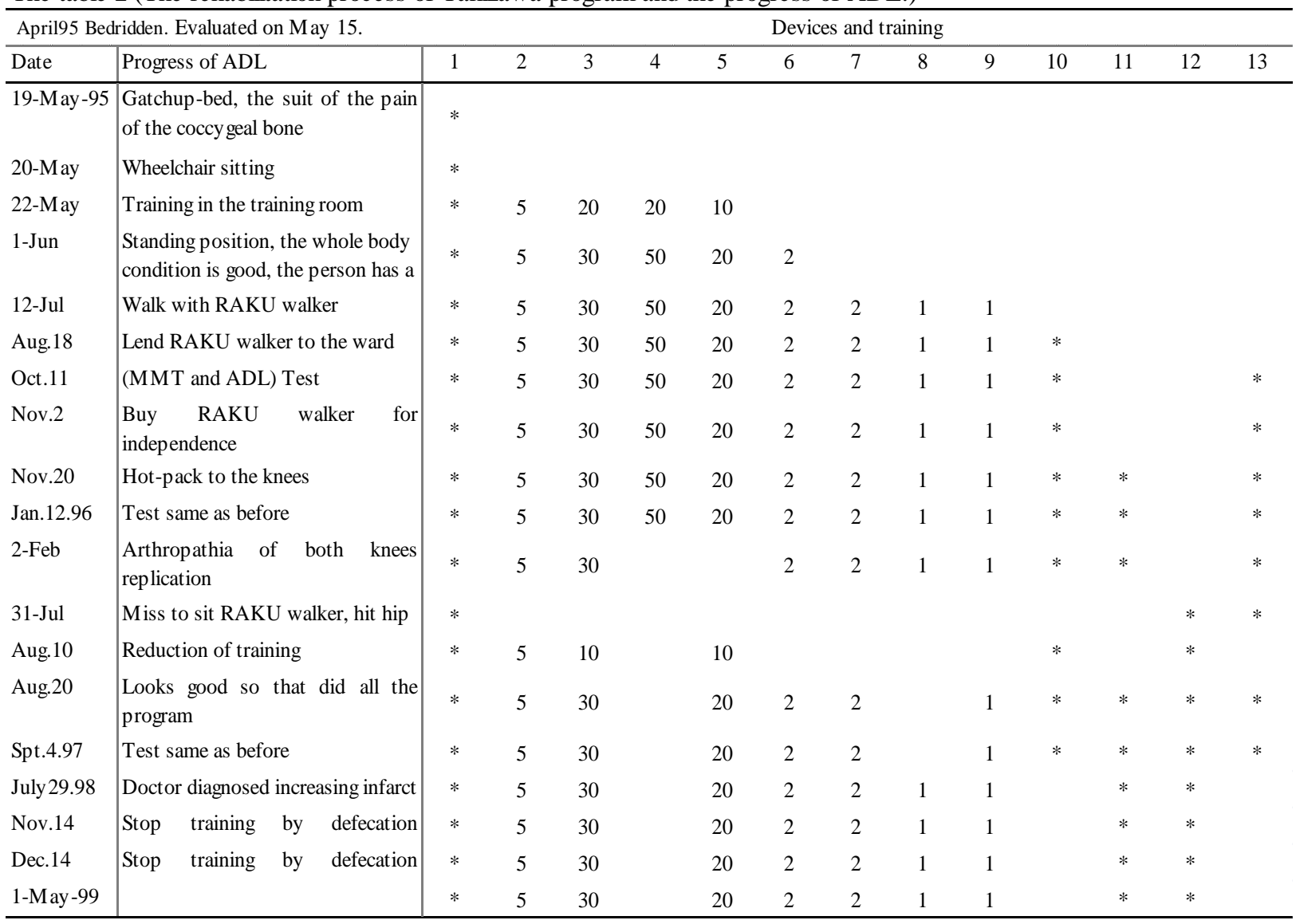

1. Positioning by Cushion. 2. Trunk training. 3. Device for upper extremities. 4. Devices for lower extremities. 5. Weight band $0.5 \mathrm{Kg}$. 6. Parallel bars for standing position training for 10 seconds.. 7. Frontback walk on the parallel bars. 8. Side walk on the parallel bars. 9. RAKU walker walking around the parallel bars. 10. RAKU walker walking freely. 11. Hot pack. 12. Microwave. 13. Show the independence of toilet activities. "*" shows the enforcement. Numbers in the column show the number of times for training. 


\section{Results}

On May 11, 1995, a woman 91 years old had transferred by stretcher from the other hospital. On July 12, she reacquired walking by motivative exercise and Takizawa method. She had difficulty in lifting a pickup style walker. Also, she could not use a four-wheeled walker since it slid ahead of her. A trial use of the RAKU walker conformed to her. The physiotherapist evaluated on October 11, 1995 and the result are shown in the Table 1-2. From October 11, 1995 to July 29, 1998, by using the RAKU walker, she had accomplished ADL and independent toilet activities. Evaluations by September 4, 1997 had not changed much. The doctor diagnosed increasing infarctions on July 29, 1998 due to the dominant atrophy of the interosseous muscles.

\section{Conclusions}

The result by this method is obtained with the guidance of a particular physiotherapist (73 years old). However, there is a possibility of the enforcement of this method anytime and by anyone through the regular guidance based on the evaluation. We defined both Takizawa method and Motivative exercise at the 5 th meeting of the 21 st century rehabilitation study meeting ${ }^{4)}$. We will investigate what kind of change that is caused to the patients by this treatment, due to developing the inspection devices hereafter. The Takizawa method for Geriatric patients is considerable to prevent or improve contracture of central paralysis from both the study and from experiences over the past 30 years. Thereupon, the in-depth research and hypothesis conducted in analyzing the mechanism to be a topic of discussion for several years. The proof that the paralyzed part of the nervous system may resume function due to revitalizing of neuronal circuits as a result of the exercise has been shown in this report. .

\section{REFERENCES}

1) Kimura T. Rehabilitation of Spinal Cord Injury In the National Rehabilitation Center For the Disabled Japan. Paper presented at: The International Seminar of WHO. Nov. 11. 1997. Tokyo. 57-60

2) Takizawa S, Takizawa K. The devices for rehabilitation centering of the walker. Journal of Fujisawa Medical Association. April 1993, Fujisawa, Japan. 5-7

3) Takizawa S, Kimura T, Kijima H, Takizawa K, et al. The development of devices for the MOTIVATIVE exercise of impaired extremities. CSUN's Fifteenth Annual International Conference. Los Angeles. March 22. 2000: Session 166.

4) Takizawa S, Kijima H, Kimura T, Takizawa K, et al, The study of the motivative exercise and the Takizawa method by the 21st Century Rehabilitation Study Meeting in Japan. CSUN's sixteenth Annual International Conference. Los Angeles. March 22. 2001: Session 163.

This article was a lecture article of The $1^{\text {st }}$ World Congress of the International Society of Physical and Rehabilitation Medicine (The $1^{\text {st }}$ ISPRM) at Amsterdam, the Netherlands, July 7-13, 2001. It was accepted as the lecture article after the pre review by the reviewers and published by the Monduzzi Editore S.p.A (The present name: Medimond S.r.1.) as the Proceedings of the $1^{\text {st }}$ ISPRM Congress PP 743-746. We filled out the occupations at that time.

The date of the publish permission with the review for the BIOPHILIA: March 17, 2015

The Biophilia editorial board obtained the publication request by the author and copyright holder's permission, and published this article after the review. 